\title{
Engaging clinicians and patients to assess and improve frailty measurement in adults with end stage renal disease
}

Sarah Van Pilsum Rasmussen ${ }^{1}$, Jonathan Konel', Fatima Warsame ${ }^{2}$, Hao Ying ${ }^{1}$, Brian Buta ${ }^{3}$, Christine Haugen ${ }^{1}$, Elizabeth King ${ }^{1}$, Sandra DiBrito ${ }^{1}$, Ravi Varadhann ${ }^{4}$, Leocadio Rodríguez-Mañas ${ }^{5}$, Jeremy D. Walston², Dorry L. Segev ${ }^{1,5^{*}}$ and Mara A. McAdams-DeMarco ${ }^{1,5,6^{*}}$ (i)

\begin{abstract}
Background: The Fried frailty phenotype, a measure of physiologic reserve defined by 5 components (exhaustion, unintentional weight loss, low physical activity, slow walking speed, and poor grip strength), is associated with poor outcomes among ESRD patients. However, these 5 components may not fully capture physiologic reserve in this population. We aimed to ascertain opinions of ESRD clinicians and patients about the usefulness of the Fried frailty phenotype and interventions to improve frailty in ESRD patients, and to identify novel components to further characterize frailty in ESRD.

Methods: Clinicians who treat adults with ESRD completed a 2-round Delphi study ( $n=41$ and $n=36$, respectively; response rate $=87 \%)$. ESRD patients completed a survey at transplant evaluation $(n=460$; response rate $=81 \%)$. We compared clinician and patient opinions on the constituent components of frailty.

Results: Clinicians were more likely than patients to say that ESRD makes patients frail (97.6\% vs. 60.2\%). There was consensus among clinicians that exhaustion, low physical activity, slow walking speed, and poor grip strength characterize frailty in ESRD patients; however, 29\% of clinicians thought weight loss was not relevant. Patients were less likely than clinicians to say that the 5 Fried frailty components were relevant. Clinicians identified 10 new ESRD-specific potential components including falls (64\%), physical decline (61\%), and cognitive impairment (39\%). Clinicians (83\%) and patients (80\%) agreed that intradialytic foot-peddlers might make ESRD patients less frail.

Conclusions: There was consensus among clinicians and moderate consensus among patients that frailty is more common in ESRD. Weight loss was not seen as relevant, but new components were identified. These findings are first steps in refining the frailty phenotype and identifying interventions to improve physiologic reserve specific to ESRD patients.
\end{abstract}

Keywords: Frailty, Hemodialysis, ESRD

\footnotetext{
*Correspondence: dorry@jhmi.edu; mara@jhu.edu

'Department of Surgery, Johns Hopkins University School of Medicine,

Baltimore, MD, USA

Full list of author information is available at the end of the article
} 


\section{Background}

Frailty is a phenotype of decreased physiologic reserve resulting in a vulnerability to adverse health outcomes upon confrontation by stressors. The phenotype was originally defined and validated in older populations by Fried et al. as the presence of at least 3 of 5 components: exhaustion, unintentional weight loss, low physical activity, slow walking speed, and poor grip strength [1]. Among older adults, frailty prevalence ranges from 7 to $15 \%$ and is associated with increased risk of mortality, incident disability, hospitalizations, and falls [1-5]. Among end stage renal disease (ESRD) patients, the prevalence of the Fried frailty phenotype is 5 to 7 -fold higher than in communitydwelling older adults [6] and is associated with higher mortality, more hospitalizations, more falls, poor cognitive function, and poor health-related quality of life [6-9]. Among ESRD patients who undergo kidney transplantation $(\mathrm{KT})$, the Fried frailty phenotype is associated with worse health related quality of life and physical function at the time of KT and longer postKT hospital stay, delayed graft function, early hospital readmission, immunosuppression intolerance, and increased mortality [6, 9-15].

Despite the importance of the Fried frailty phenotype in risk stratification of clinical outcomes in ESRD patients, its predictive ability is moderate (area under the receiver operative curve $=0.70 ;$ c statistic $=0.75)[11$, 12] suggesting that the phenotype may be missing some valuable information for ESRD patients. Because the Fried frailty phenotype was developed in communitydwelling older adults, some components may not be applicable to ESRD patients, and there may be aspects of physiologic reserve in ESRD patients that are not characterized by this phenotype. Supporting this hypothesis, we have previously found that not all 5 components contribute to the value of the Fried phenotype in predicting mortality risk among KT recipients [16].

A more accurate measure of frailty among ESRD patients will improve risk prediction, aid in clinical decision-making, develop targeted patient counseling, and identify interventions to improve physiologic reserve. Both ESRD patient and clinician opinions are needed to identify which of the 5 Fried components are mechanistically and biologically plausible, and which ESRD-specific components should be added or substituted in the phenotypic description of frailty to improve characterization of physiologic reserve in this population.

The primary goal of this study was to ascertain the opinions of experts who care for patients with ESRD and of ESRD patients pursuing kidney transplantation about the usefulness of the Fried frailty phenotype, and which novel components may further characterize frailty among ESRD patients. Additionally, we sought to elicit the opinions of these clinicians and patients on the effectiveness of and patient interest in interventions to improve frailty in ESRD and transplant patients. The Delphi method [17], an iterative survey design that builds consensus among experts through a series of structured surveys, has been used to elicit opinions on frailty among geriatrics experts [18]. In this study, we used the Delphi method to evaluate clinician consensus on the constituent components of frailty in ESRD and contrast those opinions with those of ESRD patients.

\section{Methods}

\section{Delphi survey of clinicians}

Since typical Delphi panels have ranged in size from 15 to 60 participants [17], we identified 53 attending nephrologists, geriatricians, and transplant surgeons who care for adults with ESRD at Johns Hopkins. Using a two-round Delphi approach, we distributed two anonymous surveys (Additional file 1: Table S1) to clinicians at a single center 1 month apart. Responses were only collected from clinicians who said they treated adults with ESRD. The first survey was distributed to 53 participants, and the second survey was distributed to the 46 clinicians that responded to the first survey. To preserve the anonymity of the surveys, we sent the second survey to all respondents in the first survey regardless of whether they treated patients with ESRD. Participants were recruited over email and the surveys were administered online by Qualtrics (Provo, UT). In the survey, frailty was defined as "a syndrome characterized by a loss of physiologic reserve." The five Fried frailty components were also listed.

The first round Delphi survey included qualitative and quantitative questions on frailty and interventions for ESRD patients (Additional file 1: Table S1). Clinicians were asked if they would add components to or remove components from the Fried frailty definition (Additional file 2: Table S2) to characterize frailty in adults with ESRD, and if so they were asked to list the components and explain their answers. Novel components were generated from open-ended questions in the first survey and were not suggested by the researchers. Clinicians were also asked their opinions on the efficacy of and patient interest in interventions to improve frailty such as prehabilitation, and intradialytic activities such as foot peddlers. The second round Delphi survey presented participants with results from the first survey to: 1) inform participants of the current status of the group's opinion, 2) help participants identify responses that they missed or gave low importance in previous rounds, and 3) allow participants to change their opinion [17] (Additional file 3: Table S3). 


\section{Survey of ESRD patients}

To elicit patient opinions, we conducted a survey of adults (aged $\geq 18$ years old) with ESRD at the time of evaluation for KT and who had a Fried frailty phenotype measurement (Additional file 4: Table S4). All participants were recruited from Johns Hopkins. Frailty was defined as the presence of three or more of the five Fried frailty components: exhaustion, unintentional weight loss, low physical activity, slow walking speed, and poor grip strength (Additional file 4: Table S4) [1]. Surveys were conducted in person or over the phone and consisted of 10 questions about the five Fried frailty components. They were also asked 4 questions about the potential efficacy of and their interest in prehabilitation prior to KT to improve frailty. ESRD patients who were on hemodialysis at the time of the survey answered three questions about the potential efficacy of and their interest in intradialytic foot peddlers to improve frailty. Before beginning the survey, participants were told that "frailty is a syndrome characterized by a loss of physiologic reserve. People who are frail are unable to bounce back after they get sick or hurt." Participants' Fried frailty measurements were ascertained using the Fried measure of frailty (Additional file 2: Table S2) [1].

The Delphi study of clinicians and the survey of patients received human subjects research approval from the Johns Hopkins Medicine Institutional Review Board.

\section{Statistical analysis}

Summary statistics were calculated using Stata 14. Qualitative responses to the first round of the Delphi study were analyzed using NVivo. Chi-squared and Fisher's exact tests were used to examine differences between patients and clinicians, and by clinician characteristics (specialty, years in practice, and age) and patient characteristics (age, race, sex, time on dialysis, and measured Fried frailty status). To preserve anonymity, we combined the nephrologist and transplant surgeon responses; only 3 transplant surgeons who treated patients with ESRD responded to the survey. As has been previously defined, consensus was defined was $>80 \%$ agreement, and moderate consensus was defined as $60-80 \%$ agreement [17-19].

\section{Results}

\section{Survey response rates and participant characteristics: Clinicians}

The response rate for the first survey was $87 \%$ (46 of 53) and the second survey was $87 \%$ (40 of 46 ); only clinicians who responded to the first survey were asked to complete the second survey. Five respondents of the first survey and four respondents of the second survey did not treat adults with ESRD and were dropped from further analysis, resulting in a sample of 41 and 36 clinicians for the first and second surveys, respectively. Of the clinicians who responded to the survey, $61 \%$ were transplant surgeons or nephrologists, 39\% were geriatricians, $76 \%$ were $>40$ years old, $46 \%$ were female, and $83 \%$ had been in practice for $\geq 5$ years.

\section{Survey response rate and participant characteristics: ESRD patients}

There were 460 adults with ESRD who responded to the patient survey for a response rate of $80.6 \%$. Surveyed patients were $39 \%$ female and $46 \%$ white; $63 \%$ were $<60$ years old and 56\% were being treated with hemodialysis (Table 1). Only 27 patients (6\%) selfidentified as frail (mean age $=54.4$, standard deviation $(S D)=14.14)$, while 95 patients $(20 \%)$ were measured as frail by the Fried phenotype (mean age $=56.5, \mathrm{SD}=11.4$ ); of the 27 patients who self-identified as frail, 25 (93\%) were measured as either frail or intermediately frail. All participants had an eGFR of $20 \mathrm{ml} / \mathrm{min}$ or less.

\section{Opinions on frailty in adults with ESRD}

Ninety-eight percent of clinicians and $62 \%$ of ESRD patients felt that adults with ESRD are more likely to be frail than healthy adults (Table 2). There were three Fried frailty components that at least one clinician identified as not relevant to adults with ESRD: weight loss, slowed walking, and weak strength (Table 3). In both surveys, the component most frequently identified as not relevant to adults with ESRD was weight loss (20\% in the first and $29 \%$ in the second survey); in a freeresponse question, five clinicians explained that weight fluctuates in this population. Opinions on removing weight loss from the Fried frailty phenotype were associated with specialty such that nephrologists and transplant surgeons were less likely than geriatricians to want to remove weight loss $(10 \%$ vs. $50 \%, p=0.02)$. Patient perceptions of the relevance of the five Fried frailty components differed from those of clinicians; clinicians were more likely to say that weight loss $(80 \%$ vs. $62 \%)$ walking speed (92\% vs. $51 \%)$, physical activity (100\% vs. $67 \%)$, weak grip strength (97\% vs. $81 \%)$, and exhaustion $(100 \%$ vs. $80 \%$ ) were relevant to frailty among ESRD patients.

Among ESRD patients, 91\% of participants who both measured and self-identified as frail believed that adults with ESRD are more likely to be frail than healthy adults. However, 58\% of participants who measured as frail but self-identified as non-frail believed that adults with ESRD are more likely to be frail (Table 4).

\section{Novel ESRD-specific frailty components}

Clinicians identified ten novel components that potentially characterize frailty in adults with ESRD (Table 3 ). In the second survey, there was moderate 
Table 1 ESRD patient survey population characteristics by measured frailty status

\begin{tabular}{|c|c|c|c|}
\hline Participant Characteristics & $\begin{array}{l}\text { Frail n (\%) } \\
95(20.65)\end{array}$ & $\begin{array}{l}\text { Not frail n (\%) } \\
365 \text { (79.35) }\end{array}$ & $\begin{array}{l}\text { Overall } \mathrm{n}(\%) \\
460\end{array}$ \\
\hline \multicolumn{4}{|l|}{ Sex } \\
\hline Female & $35(36.8)$ & $143(19.2)$ & $178(38.7)$ \\
\hline \multicolumn{4}{|l|}{ Race } \\
\hline White & $40(42.1)$ & $173(47.4)$ & $213(46.3)$ \\
\hline African American & $50(52.6)$ & $159(43.6)$ & $209(45.4)$ \\
\hline Asian & $3(3.2)$ & $17(4.7)$ & $20(4.4)$ \\
\hline Native Hawaiian/Pacific Islander & $0(0)$ & $2(0.6)$ & $2(0.4)$ \\
\hline Other & $2(2.1)$ & $14(3.8)$ & $16(3.5)$ \\
\hline \multicolumn{4}{|l|}{ Age } \\
\hline$<30$ & $2(2.1)$ & $19(5.2)$ & $21(4.6)$ \\
\hline 30-39 & $8(8.4)$ & $37(10.1)$ & $45(9.8)$ \\
\hline $40-49$ & $16(16.8)$ & $69(18.9)$ & $85(18.5)$ \\
\hline $50-59$ & $27(28.4)$ & $113(40.0)$ & $150(30.4)$ \\
\hline $60-69$ & $34(35.8)$ & $93(25.5)$ & $127(27.6)$ \\
\hline$\geq 70$ & $8(8.4)$ & $34(9.3)$ & $42(9.1)$ \\
\hline \multicolumn{4}{|l|}{ Dialysis Type } \\
\hline Hemodialysis & $56(59.0)$ & $196(55.4)$ & $252(56.1)$ \\
\hline Peritoneal dialysis & $12(12.6)$ & $46(13.0)$ & $58(12.9)$ \\
\hline Not on dialysis & $27(28.4)$ & $112(31.6)$ & $139(31.0)$ \\
\hline \multicolumn{4}{|c|}{ Time on Dialysis Among Patients on Dialysis (years) } \\
\hline$<1$ & $14(29.8)$ & $31(17.3)$ & $45(19.9)$ \\
\hline $1-1.9$ & $21(44.7)$ & $57(31.8)$ & $78(34.5)$ \\
\hline $2-2.9$ & $7(14.9)$ & $34(19.0)$ & $41(18.1)$ \\
\hline $3-3.9$ & $1(2.1)$ & $15(8.4)$ & $16(7.1)$ \\
\hline $4-4.9$ & $3(6.4)$ & $15(8.4)$ & $18(8.0)$ \\
\hline$\geq 5$ years & $1(2.1)$ & $27(15.1)$ & $28(12.4)$ \\
\hline
\end{tabular}

consensus that history of falls (64\%) and physical decline (61\%) should be added; additionally, 39\% of clinicians identified cognitive impairment as a novel component. Nephrologists and transplant surgeons were more likely to want to include cognitive impairment and history of falls as ESRD-specific frailty components than geriatricians (cognitive impairment: $55 \%$ vs. $19 \%, p=0.04$; falls: $85 \%$ vs. $38 \%, p=0.005$ ).

\section{Intradialytic activities to improve frailty among adults with ESRD}

Among clinicians there was consensus (83\% agreement) and among ESRD patients who were on hemodialysis there was moderate consensus ( $80 \%$ agreement) that intradialytic foot peddlers will make ESRD patients on dialysis less frail (Table 2). However, there was only moderate consensus among both clinicians (69\% agreement) and patients (62\% agreement) that ESRD patients would be interested in using foot peddlers while undergoing hemodialysis.

\section{Prehabilitation to improve frailty among adults undergoing kidney transplant}

There was consensus among both clinicians (97\% agreement) and patients (94\% agreement) that pre-KT prehabilitation will help patients undergoing transplantation (Table 2) and that prehabilitation would make ESRD patients less frail ( $100 \%$ vs. $84 \%$, Table 2$)$. Among clinicians there was consensus (97\% agreement) and among patients there was moderate consensus (80\% agreement) that patients would be interested in preKT prehabilitation (Table 2).

\section{Discussion}

In this study to elicit opinions about frailty in ESRD patients, there was consensus among clinicians who care for 
Table 2 Clinician and patient opinions on frailty in adults with ESRD and on intradialytic interventions

\begin{tabular}{|c|c|c|c|}
\hline & $\%$ Clinicians in first survey & $\%$ Clinicians in second survey & \% Patients \\
\hline \multicolumn{4}{|c|}{ Are ESRD patients more likely to be frail than healthy adults? } \\
\hline More likely & 97.6 & * & 61.8 \\
\hline Less likely & 0 & * & 9.13 \\
\hline About the same & 2.4 & * & 29.0 \\
\hline \multicolumn{4}{|l|}{ Relevance of frailty component } \\
\hline Weight loss & 80.0 & 71.4 & 61.6 \\
\hline Walking speed & 92.5 & 94.3 & 51.2 \\
\hline Physical activity & 100 & * & 67.0 \\
\hline Weak Strength & 97.5 & 100 & 81.2 \\
\hline Exhaustion & 100 & * & 80.0 \\
\hline \multicolumn{4}{|l|}{ Opinions on Interventions to improve frailty } \\
\hline Patients would be interested in foot peddlers & 69.2 & * & 62.5 \\
\hline Foot peddlers would make patients less frail & 83.3 & * & 79.7 \\
\hline \multicolumn{4}{|l|}{ Opinions on prehabilitation to improve frailty } \\
\hline Patients would be interested in prehabilitation & 97.1 & * & 80.2 \\
\hline Prehabilitation would make ESRD patients less frail & 97.1 & * & 84.5 \\
\hline Prehabilitation would help ESRD patients & 100 & * & 93.8 \\
\hline
\end{tabular}

"Questions on the relevance of frailty components were only included in the second survey of clinicians if there was not total agreement in the first survey. Questions on interventions, prehabilitation and prevalence of frailty in ESRD patients were not included in the second survey due to consensus and moderate consensus ( $>60 \%$ agreement) reached in the first survey

Table 3 Clinician opinions on Fried Frailty components and novel ESRD-specific frailty components

\begin{tabular}{llll}
\hline $\begin{array}{l}\text { A. Percentage of clinicians identifying components as not relevant to adults with ESRD in the first and second survey } \\
\text { Component }\end{array}$ & $\begin{array}{l}\text { \% identifying in 1st survey } \\
(\mathbf{n}=\mathbf{4 1})\end{array}$ & $\begin{array}{l}\text { \% identifying in } \mathbf{2 n d} \text { survey } \\
(\mathbf{n}=\mathbf{3 6})\end{array}$ & $\begin{array}{l}\text { Qualitative explanations for irrelevance } \\
(\mathbf{1} \text { st survey) }\end{array}$ \\
$\begin{array}{l}\text { Unintentional Weight Loss } \\
20.0\end{array}$ & 28.6 & $\begin{array}{l}\text { - Weight fluctuates in this population }(n=5) \\
\text { - Not relevant to ESRD population }(n=2)\end{array}$ \\
Slowed Walking & 7.5 & 6.0 & Not relevant to ESRD Population $(n=2)$ \\
Weak Strength & 2.5 & 0 & Generalized fatigue is more relevant $(n=1)$ \\
Low Physical Activity & 0 & $*$ & $n / a$
\end{tabular}

B. Novel ESRD-specific components suggested by clinicians in the first round, and percentage of clinicians wanting to add each component by specialty in the second round

\begin{tabular}{llll}
$\begin{array}{l}\text { 1st survey: components } \\
\text { identified }\end{array}$ & $\begin{array}{l}\text { 2nd survey: \% wanting to add } \\
\text { component }\end{array}$ & \% wanting to add component by specialty \\
History of falls & 63.9 & Geriatricians & Nephrologists and Transplant Surgeons \\
Physical decline & 61.1 & 37.5 & 85.0 \\
Cognitive Impairment & 38.9 & 50.0 & 70.0 \\
Nutrition, diet & 36.1 & 18.8 & 55.0 \\
Albumin & 16.7 & 25.0 & 45.0 \\
Health care utilization & 11.1 & 6.2 & 25.0 \\
Metabolic bone disease & 5.6 & 12.5 & 10.0 \\
Excess fluid & 2.8 & 0 & 10.0 \\
Ultrafiltration & 2.8 & 0 & 5.0 \\
\hline
\end{tabular}

"Questions on the relevance of frailty components were only included in the second survey of clinicians if there was not total agreement in the first survey 
Table $\mathbf{4}$ Characteristics of ESRD patients by measured and self-identified frailty status

\begin{tabular}{|c|c|c|c|c|}
\hline $\begin{array}{l}\text { Measured as Frail } \\
\text { Self-identified as frail } \\
N\end{array}$ & $\begin{array}{l}\text { Yes } \\
\text { Yes } \\
12\end{array}$ & $\begin{array}{l}\text { Yes } \\
\text { No } \\
83\end{array}$ & $\begin{array}{l}\text { No } \\
\text { Yes } \\
15\end{array}$ & $\begin{array}{l}\text { No } \\
\text { No } \\
350\end{array}$ \\
\hline Age (median (IQR)) & $\begin{array}{l}52.9 \\
(44.1-66.1)\end{array}$ & $\begin{array}{l}59.0 \\
(49.5-65.6)\end{array}$ & $\begin{array}{l}56.9 \\
(48.8-65.4)\end{array}$ & $\begin{array}{l}54.5 \\
(46.7-64.3)\end{array}$ \\
\hline Male & $58.3 \%$ & $63.9 \%$ & $66.7 \%$ & $60.6 \%$ \\
\hline \multicolumn{5}{|l|}{ Race } \\
\hline White/Caucasian & $41.7 \%$ & $42.2 \%$ & $46.7 \%$ & $47.4 \%$ \\
\hline Black/African American & $58.3 \%$ & $51.8 \%$ & $46.7 \%$ & $43.4 \%$ \\
\hline Other & $0 \%$ & $6.0 \%$ & $6.7 \%$ & $9.2 \%$ \\
\hline \multicolumn{5}{|c|}{ Are ESRD patients more likely to be frail than healthy adults? } \\
\hline More likely & $90.9 \%$ & $58.2 \%$ & $73.3 \%$ & $61.2 \%$ \\
\hline Less likely & $0 \%$ & $3.8 \%$ & $0 \%$ & $11.2 \%$ \\
\hline About the same & $9.1 \%$ & $37.9 \%$ & $26.7 \%$ & $27.6 \%$ \\
\hline
\end{tabular}

this population, and moderate consensus among surveyed adults with ESRD, that ESRD patients are more likely to be frail than healthy adults. There was some discordance between self-identification and measurement of frailty status, and participants who identified as frail were more likely to think that adults with ESRD are more likely to be frail, regardless of their own measured frailty status.

Four of the five Fried frailty components (exhaustion, low activity, slow walking speed and grip strength) were thought to be relevant to adults with ESRD, and clinicians were more likely to believe those four components were relevant. There was only moderate consensus among both clinicians and patients that unintentional weight loss characterizes frailty in this population, likely given the weight fluctuations and fluid shifts that are common in ESRD patients. Other possible ESRDspecific frailty components that were identified included history of falls, physical decline, and poor cognitive impairment. Interestingly, the novel components identified are less likely to be measures of kidney disease, but rather are downstream effects of ESRD. Finally, there was consensus among the clinicians that intradialytic foot peddlers and prehabilitation prior to KT would be effective interventions for reducing the burden of frailty in this vulnerable population.

Prior research has shown that frailty, as measured by the Fried phenotype, is an important predictor of ESRD and transplant patient outcomes [5-13]. A prior study has identified 67 different instruments for the study of frailty among older adults [20]; however, none of these instruments are specific to patients with ESRD. Our findings suggest that physicians and patients believe that exhaustion, low physical activity, slow walking speed, and poor grip strength were relevant to ESRD patients but that weight loss was possibly not relevant.
Interventions such as intradialytic activities and prehabilitation have been proposed to improve frailty among adults with ESRD [21, 22]. Our findings are consistent with a previous qualitative study of hemodialysis patients that reported patient support for intradialytic exercise [21]. We extended these findings to include ESRD patient and clinician opinions on whether intradialytic exercise using a foot peddler would improve physiologic reserve. Additionally, we included clinician and patient opinions on prehabilitation prior to transplantation; there was consensus among both groups that prehabilitation would help ESRD patients and make them less frail. This perception is consistent with studies that demonstrate that frailty is associated with physical functioning in older adults [1].

Clinicians had higher levels of consensus on all issues relating to frailty in ESRD than did patients. Given the discordance between frailty status and self-perception of frailty found in this study, the lower levels of consensus among patients might be related to a lack of awareness of frailty and its prevalence in ESRD.

A strength of this study was the two round Delphi study design of clinicians caring for ESRD patients, which uses both qualitative and quantitative methods to elicit opinion and facilitate consensus. Additionally, this is the first study to directly survey ESRD patients on their opinions regarding what makes them frail. This study's main limitation was the single-center design with respect to sampling patients and clinicians at Johns Hopkins. Perspectives of clinicians and patients from one center may not be generalizable. The wording of the survey items, particularly those questions relating to clinician perceptions of acceptability of interventions to improve frailty, may have elicited an affirmative response.

Nephrologists, transplant surgeons and geriatricians may all have incomplete perspectives on frailty in ESRD given the limited populations with whom they work. 
However, all clinician participants had experience treating adults with ESRD, as this was an inclusion criterion for this study. Despite these limitations, $85 \%$ of clinicians who treat adults with ESRD at Johns Hopkins were represented in the study, and the sample size was consistent with or larger than prior Delphi studies [17, 23].

As the target population for this study was ESRD patients who were pursuing kidney transplantation, patients included in this study were all under evaluation for kidney transplantation. With an $80.6 \%$ response rate, we believe this study is representative of ESRD patients pursuing kidney transplantation at our center. Patients being evaluated for transplantation might be concerned that their appearing frail would affect their listing for transplantation, which could bias their responses. However, patients were assured that none of their responses would affect any aspect of their care during evaluation, including their access to transplantation. Furthermore, the questions in this survey are part of a longer 45-min assessment consisting of 252 questions. Thus the likelihood of responses being biased by a desire to appear not frail should be mitigated. Additionally, ESRD patients were not asked to suggest potential novel ESRD-specific frailty components.

The Fried frailty measure is just one of many measures that could be used in an ESRD setting. However, in a recent review of 67 different frailty assessment instruments, the Fried phenotype was the most cited instrument [20]. The Fried phenotype is commonly used in ESRD research [24-26] and its biological basis is well established [27]. Given its prevalence, particularly in ESRD research, we sought to assess its appropriateness in an ESRD setting.

This study is one step in the process of refining the definition of frailty in ESRD. This process should also include structured reviews and qualitative studies to elicit further themes relating to frailty in ESRD. Any new measure of frailty in ESRD patients should be thoroughly validated before informing clinical decisions. Likewise, any new components added to this measure should be further studied and operationalized prior to its inclusion in a definition of frailty.

In a given population, the clinical usefulness of a definition of frailty depends on the relevance of its components to the physiology of that population. Among ESRD patients and clinicians who care for them, there is consensus that many Fried frailty components measure decline of physiologic reserve in ESRD patients; however, the complex physiologic issues experienced by patients with ESRD may make other aspects of physiologic reserve, like history of falls or physical decline, relevant in this population. An ESRD-specific measure of frailty could improve risk prediction in ESRD and transplant patients, and the patient and clinician opinions elicited in this study should inform the development of such a measure.

\section{Conclusions}

Clinicians and patients agreed that frailty is more common among adults with ESRD than the general population. Unintentional weight loss was seen as less relevant to characterizing frailty in adults with ESRD, but clinicians identified history of falls, physical decline, and cognitive impairment as possible new components of frailty in this population. Clinicians and patients agreed that intradialytic foot peddlers would make ESRD patients less frail. These findings contribute to the refining of the frailty phenotype for ESRD patients, and to the identification of interventions to improve physiologic reserve in this population.

\section{Additional files}

Additional file 1: Table S1. Delphi Study Surveys of Clinicians who treat adults with ESRD: First Survey. (DOCX $86 \mathrm{~kb}$ )

Additional file 2: Table S2. Validated Fried Frailty Assessment Tool. (DOCX $20 \mathrm{~kb}$ )

Additional file 3: Table S3. Delphi Study Survey of Clinicians who treat adults with ESRD: Second Survey. (DOCX 74 kb)

Additional file 4: Table S4. Description of data: Survey of Adults with ESRD undergoing hemodialysis. (DOCX 83 kb)

\section{Abbreviations}

ESRD: End stage renal disease; KT: Kidney transplantation; SD: Standard deviation

\section{Acknowledgments}

Not applicable

\section{Funding}

Dorry Segev was supported by NIH grant R01AG042504 and K24DK101828. Mara McAdams-DeMarco was supported by Johns Hopkins University Claude D. Pepper Older Americans Independence Center, NIH P30-AG021334, NIH K01AG043501, and NIH R01AG055781. Christine Haugen was supported by NIH T32DK007732. Sandra DiBrito was supported by NIH F32DK105600. Leocadio Rodríguez-Mañas was supported by CIBERFES (CB16/10/00464), FEDER.

\section{Availability of data and materials}

The datasets used and/or analyzed during the current study are available from the corresponding author on reasonable request.

\section{Authors' contributions}

SVPR, JK, FW, DS and MMD contributed to conception, design, and analysis of the data and drafting of the article. SVPR, JK, FW, HY, CH, BB, EK, SD, RV, LRM, JW, DS, and MMD contributed to the interpretation of data, revision of the article, providing intellectual content to the article, and final approval of the manuscript.

\section{Ethics approval and consent to participate}

This study received human subjects research approval from the Johns Hopkins Medicine Institutional Review Board (IRB00090487 and

NA_00015758). All study participants provided written informed consent prior to participation.

Consent for publication

Not applicable

Competing interests

The authors declare that they have no competing interests. 


\section{Publisher's Note}

Springer Nature remains neutral with regard to jurisdictional claims in published maps and institutional affiliations.

\section{Author details}

'Department of Surgery, Johns Hopkins University School of Medicine, Baltimore, MD, USA. ${ }^{2}$ Department of Epidemiology, Johns Hopkins School of Public Health, Baltimore, MD, USA. ${ }^{3}$ Department of Medicine, Johns Hopkins University School of Medicine, Baltimore, MD, USA. ${ }^{4}$ Department of Oncology, Sidney Kimmel Comprehensive Cancer Center, Baltimore, MD, USA. ${ }^{5}$ Hospital Universitario de Getafe, Madrid, Spain. ${ }^{6}$ Department of Epidemiology, 615 N. Wolfe St, W6033, Baltimore, MD 21205, USA.

Received: 12 June 2017 Accepted: 21 December 2017

Published online: 12 January 2018

\section{References}

1. Fried LP, Tangen CM, Walston J, Newman AB, Hirsch C, Gottdiener Seeman T, Tracy R, Kop WJ, Burke G, et al. Frailty in older adults: evidence for a phenotype. J Gerontol A Biol Sci Med Sci. 2001;56(3):M146-56.

2. Diaz de Leon Gonzalez E, Tamez Perez HE, Gutierrez Hermosillo H, Cedillo Rodriguez JA, Torres G. Frailty and its association with mortality, hospitalization and functional dependence in Mexicans aged 60-years or older. Medicina clinica. 2012;138(11):468-74.

3. Bouillon K, Sabia S, Jokela M, Gale CR, Singh-Manoux A, Shipley MJ, Kivimaki M, Batty GD. Validating a widely used measure of frailty: are all subcomponents necessary? Evidence from the Whitehall II cohort study. Age (Dordr). 2013;35(4):1457-65.

4. Mitnitski A, Fallah N, Rockwood MR, Rockwood K. Transitions in cognitive status in relation to frailty in older adults: a comparison of three frailty measures. J Nutr Health Aging. 2011;15(10):863-7.

5. Bandeen-Roche K, Seplaki CL, Huang J, Buta B, Kalyani RR, Varadhan R, Xue QL, Walston JD, Kasper JD. Frailty in older adults: a nationally representative profile in the United States. J Gerontol A Biol Sci Med Sci. 2015:70(11):1427-34

6. McAdams-DeMarco MA, Law A, Salter ML, Boyarsky B, Gimenez L, Jaar BG, Walston JD, Segev DL. Frailty as a novel predictor of mortality and hospitalization in individuals of all ages undergoing hemodialysis. J Am Geriatr Soc. 2013;61(6):896-901.

7. McAdams-DeMarco MA, Suresh S, Law A, Salter ML, Gimenez LF, Jaar BG, Walston JD, Segev DL. Frailty and falls among adult patients undergoing chronic hemodialysis: a prospective cohort study. BMC Nephrol. 2013;14:224.

8. McAdams-DeMarco MA, Tan J, Salter ML, Gross A, Meoni LA, Jaar BG, Kao WH, Parekh RS, Segev DL, Sozio SM. Frailty and cognitive function in incident Hemodialysis patients. Clin J Am Soc Nephrol. 2015;10(12):2181-9.

9. McAdams-DeMarco MA, King EA, Luo X, Haugen C, DiBrito S, Shaffer A, Kucirka LM, Desai NM, Dagher NN, Lonze BE, et al. Frailty, length of stay, and mortality in kidney transplant recipients: a National Registry and prospective cohort study. Ann Surg. 2016;

10. Garonzik-Wang JM, Govindan P, Grinnan JW, Liu M, Ali HM, Chakraborty A, Jain V, Ros RL, James NT, Kucirka LM, et al. Frailty and delayed graft function in kidney transplant recipients. Arch Surg. 2012;147(2):190-3.

11. McAdams-DeMarco MA, Law A, King E, Orandi B, Salter M, Gupta N, Chow E, Alachkar N, Desai N, Varadhan R, et al. Frailty and mortality in kidney transplant recipients. Am J Transplant. 2015;15(1):149-54.

12. McAdams-DeMarco MA, Law A, Salter ML, Chow E, Grams M, Walston J, Segev DL. Frailty and early hospital readmission after kidney transplantation. Am J Transplant. 2013;13(8):2091-5.

13. McAdams-DeMarco MA, Law A, Tan J, Delp C, King EA, Orandi B, Salter M, Alachkar N, Desai N, Grams M, et al. Frailty, mycophenolate reduction, and graft loss in kidney transplant recipients. Transplantation. 2015;99(4):805-10.

14. Nastasi AJ, McAdams-DeMarco MA, Schrack J, Ying H, Olorundare I, Warsame F, Mountford A, Haugen CE, González Fernández M, Norman SP, et al. Pre-kidney transplant lower extremity impairment and post-kidney transplant mortality. Am J Transplant. 2018;18:189-96.

15. McAdams-DeMarco MA, Olorundare IO, Ying H, Warsame F, Haugen CE, Hall R, Garonzik-Wang JM, Desai NM, Walston JD, Norman SP, et al. Frailty and Postkidney transplant health-related quality of life. Transplantation, Online First. 2017;
16. McAdams-DeMarco MYH, Olorundare I, King EA, Haugen C, Buta B, Gross AL, Kalyani R, Desai NM, Dagher N, Lonze BE, Montgomery RA, BandeenRoche K, Walston J, Segev DL. Individual frailty components and mortality in kidney transplant recipients. Transplantation. 2017:101(9):2126-32.

17. Hasson F, Keeney S, McKenna H. Research guidelines for the Delphi survey technique. J Adv Nurs. 2000:32(4):1008-15.

18. Rodriguez-Manas L, Feart C, Mann G, Vina J, Chatterji S, Chodzko-Zajko W, Gonzalez-Colaco Harmand M, Bergman H, Carcaillon L, Nicholson C, et al. Searching for an operational definition of frailty: a Delphi method based consensus statement: the frailty operative definition-consensus conference project. J Gerontol A Biol Sci Med Sci. 2013:68(1):62-7.

19. Keeney S, Hasson F, McKenna H. Consulting the oracle: ten lessons from using the Delphi technique in nursing research. J Adv Nurs. 2006; 53(2):205-12.

20. Buta BJ, Walston JD, Godino JG, Park M, Kalyani RR, Xue Q-L, Bandeen-Roche K, Varadhan R. Frailty assessment instruments: systematic characterization of the uses and contexts of highly-cited instruments. Ageing Res Rev. 2016;26:53-61.

21. Thompson S, Tonelli M, Klarenbach S, Molzahn A. A qualitative study to explore patient and staff perceptions of Intradialytic exercise. Clin J Am Soc Nephrol. 2016;11(6):1024-33.

22. Rumer KK, Saraswathula A, Melcher ML. Prehabilitation in our most frail surgical patients: are wearable fitness devices the next frontier? Curr Opin Organ Transplant. 2016;21(2):188-93.

23. Jones J, Hunter D. Consensus methods for medical and health services research. BMJ. 1995;311(7001):376-80.

24. Johansen KL, Chertow GM, Jin C, Kutner NG. Significance of frailty among dialysis patients. J Am Soc Nephrol. 2007;18(11):2960-7.

25. Shlipak MG, Stehman-Breen C, Fried LF, Song X, Siscovick D, Fried LP, Psaty $B M$, Newman AB. The presence of frailty in elderly persons with chronic renal insufficiency. Am J Kidney Dis. 2004;43(5):861-7.

26. Wilhelm-Leen ER, Hall YN, Tamura MK, Chertow GM. Frailty and chronic kidney disease: the third National Health and nutrition evaluation survey. Am J Med. 2009:122(7):664-71. e662

27. Walston J, McBurnie M, Newman A, et al. Frailty and activation of the inflammation and coagulation systems with and without clinical comorbidities: results from the cardiovascular health study. Arch Intern Med. 2002:162(20):2333-41.

\section{Submit your next manuscript to BioMed Central and we will help you at every step:}

- We accept pre-submission inquiries

- Our selector tool helps you to find the most relevant journal

- We provide round the clock customer support

- Convenient online submission

- Thorough peer review

- Inclusion in PubMed and all major indexing services

- Maximum visibility for your research

Submit your manuscript at www.biomedcentral.com/submit
Biomed Central 